\title{
Projeto Identidade e Inclusão Social: do desafio curricular à ousadia interdisciplinar
}

\author{
Eliana Müller de Mello* \\ Denise Regina Quaresma da Silva**
}

Resumo: Neste trabalho, discutem-se os conceitos de poder, subjetivação e (a)normalidade, bem como os conceitos de cultura em relação à temática da Diferença e da Inclusão Social. Tal discussão é feita no sentido de expor a fundamentação de uma pesquisa sobre a produção da identidade da mulher no imaginário social através de três eixos norteadores da pesquisa: midiático, biológico e territorial. Pretende-se uma análise de como se constrói um discurso sobre os sujeitos "diferentes", atentando para os vazios do simbólico em relação à normalidade e à inclusão.

Palavras-chave: Inclusão, Representação, Discurso, Cultura.

Abstract: In this research the concepts of dominion are argued, subjectivity and (ab)normality, as well as the concepts of culture in relation to thematic of the Difference and the social inclusion. Such quarrel is made in the direction to display the recital of an in progress research on the production of the identity imaginary

* Mestre em Educação, Especialista em Linguística Aplicada e em Metodologia de Ensino, graduada em Letras e Literaturas; professora da Escola de Educação Básica Feevale - Escola de Aplicação; coordenadora do projeto Identidade e Inclusão Social; pesquisadora voluntária da Universidade Feevale; ganhadora de 4 prêmios nacionais e 1 prêmio internacional de reconhecimento na educação; autora de capítulos de livros referentes às temáticas Interdisciplinaridade, Currículo, Identidade, Gênero e Inclusão. E-mail: elianad@feevale.br

** Psicóloga, Psicanalista Membro do Círculo Psicanalítico do RGS, Mestre e Doutora em Educação; professora adjunta do curso de Psicologia, Pedagogia, Ensino da Arte na Diversidade e Pós-graduação em Arteterapia e Educação Infantil da Universidade Feevale; coautora dos livros: "Desdobrando o avesso da psicanálise: Relaçốes com a Educação", "Crianças Psicóticas e Autistas: a construção de uma escola", autora do livro: "Fracasso" Escolar: que lugar é esse?” E-mail: denisequaresma@feevale.br 
woman in social through the three axles central of the research: the media, biological and territorial. An analysis is intended of as if it constructs a speech on "the different" citizens, attempting against for the emptinesses of the symbolic one in relation to normality and inclusion.

Keywords: Inclusion, Representation, Speech, Culture.

\section{Introdução}

As Diretrizes Curriculares Nacionais - Parecer CEB/CNB $n^{\circ} .15 / 98$, instituídas pela Resolução n ${ }^{\circ}$. 4/98, entre outras disposições, determinam que os currículos se organizem em áreas - "a base nacional comum dos currículos será organizada em áreas de conhecimento" - estruturadas pelos princípios pedagógicos da interdisciplinaridade, da contextualização, da identidade, da diversidade e autonomia, redefinindo, de modo radical, a forma como têm sido realizadas a seleção e organização de conteúdos e a definição de metodologias nas escolas em nosso país.

Entre os princípios pedagógicos que estruturam as áreas de conhecimento destaca-se como eixo articulador a interdisciplinaridade. Para observância da interdisciplinaridade é preciso entender que as disciplinas escolares resultam de recortes e seleções arbitrários, historicamente constituídos, expressões de interesses e relações de poder que ressaltam, ocultam ou negam saberes, mas que constituem o currículo escolar.

Todavia, é importante deixar claro que a prática docente, ao adotar a interdisciplinaridade como metodologia no desenvolvimento do currículo escolar, não significa o abandono das disciplinas nem supõe para o professor uma "pluriespecialização"bem difícil de se imaginar, com o risco do sincretismo e da superficialidade. Para maior consciência da realidade, para que os fenômenos complexos sejam observados, vistos, entendidos e descritos torna-se cada vez mais importante a confrontação de 
olhares plurais na observação da situação de aprendizagem. Daí a necessidade de um trabalho de equipe realmente interdisciplinar.

Nesse sentido, a contextualização - outro princípio pedagógico que rege a articulação das disciplinas escolares - não deve ser entendida como uma proposta de esvaziamento, uma proposta redutora do processo ensino-aprendizagem, circunscrevendo-o ao que está no redor imediato do aluno, suas experiências e vivências. Um trabalho contextualizado parte do saber dos alunos para desenvolver competências que venham a ampliar este saber inicial. Um saber que situe os alunos num campo mais amplo de conhecimentos, de modo que possam efetivamente se integrar na sociedade, atuando, interagindo e interferindo sobre ela.

Contudo, é importante ressaltar que essa autonomia implica planejamento conjunto e integrado da escola, expressão de um compromisso tácito entre os agentes envolvidos sobre objetivos compartilhados, considerando a especificidade, as necessidades e as demandas de seu corpo docente e discente, criando expressão própria e local ao disposto na base nacional comum. Esses pressupostos justificam e esclarecem a opção pela organização do currículo em áreas que congregam disciplinas com objetos comuns de estudo, capazes, portanto, de estabelecer um diálogo produtivo do ponto de vista do trabalho pedagógico e que podem estabelecer também um diálogo entre si enquanto áreas.

Uma das articulações possíveis é a de diversos campos de conhecimento congregados a partir de eixos conceituais. A articulação do currículo a partir de conceitos-chave, sem dúvida, dá uma organicidade ao planejamento curricular. No entanto, é necessário um planejamento conjunto que possibilite a eleição de um eixo integrador, que pode ser um objeto de conhecimento, um projeto de intervenção e, principalmente, o desenvolvimento de uma compreensão da realidade sob a ótica da globalidade e da complexidade, uma perspectiva holística da própria realidade.

Uma experiência, nessa visão interdisciplinar, é realizada na Escola de Educação Básica Feevale - Escola de Aplicação, através do projeto "Identidade e Inclusão Social". Essa metodologia de ensino por projetos consiste basicamente no trabalho coletivo 
e no princípio de que as várias ciências devem contribuir para o estudo de determinados temas que orientam todo o trabalho escolar. Nesse trabalho por projetos é respeitada a especificidade de cada área do conhecimento, mas, para superar a fragmentação dos saberes, procura-se estabelecer e compreender a relação entre uma "totalização em construção" a ser perseguida e novas relações de colaboração integrada de diferentes especialistas que trazem a sua contribuição para a análise de determinada temática, sugerida pelo estudo da realidade que antecede à construção curricular.

Projeto vem de projetar, projetar-se, atirar-se para frente. $\mathrm{Na}$ prática, elaborar um projeto é o mesmo que elaborar um plano para realizar determinada ideia. Portanto, um projeto supóe a realização de algo que não existe, um futuro possível. Tem a ver com a realidade em curso e com a utopia possível, realizável, concreta. Dificilmente os integrantes de uma escola escolherão trabalhar num projeto da escola se ele não foi a extensão de seu próprio projeto de vida. Trabalhar com projetos na Escola de Aplicação exige um envolvimento muito grande de todos os parceiros e supõe algo mais do que apenas assistir ou ministrar aulas. Além do conteúdo propriamente dito de cada projeto, conta muito o processo de elaboração, execução e avaliação. Portanto, esse processo também produz aprendizagens novas, pois a própria organização das atividades pedagógicas deve ser encarada a partir da perspectiva do trabalho com projetos. De fato, respostas a perguntas tão frequentemente formuladas pelos alunos, em diferentes níveis, como "Para que estudar Matemática? E Português? E História? E Química?" não podem mais ter como referência o aumento do conhecimento ou da cultura, ou ainda, mais pragmaticamente, a aprovação nos exames. A justificativa dos conteúdos disciplinares a serem estudados deve "fundar-se em elementos mais significativos para os estudantes, e nadaé mais adequado para isso do que a referência aos projetos de vida de cada um deles, integrados simbioticamente em sua realização aos projetos pedagógicos das unidades escolares” (HERNANDEZ, 1998, p.75).

A modalidade de articulação dos conhecimentos por projetos é uma forma de organizar a atividade de ensino-aprendizagem e implica considerar que tais conhecimentos não se ordenam para sua compreensão de uma forma rígida, nem em função de algumas 
referências disciplinares preestabelecidas ou de uma homogeneização dos alunos. A função do projeto é favorecer a criação de estratégias de organização dos conhecimentos escolares em relação a: 1) o tratamento da informação, e 2) a relação entre os diferentes conteúdos em torno de problemas ou hipóteses que facilitem aos alunos a construção de seus conhecimentos, a transformação da informação procedente dos diferentes saberes disciplinares em conhecimentos próprios. É necessário destacar o fato de que as diferentes fases e atividades que se devam desenvolver num projeto ajudam os alunos a serem conscientes de seu processo de aprendizagem e exige do professorado responder aos desafios que estabelece uma estruturação muito mais aberta e flexível dos conteúdos escolares" (HERNANDEZ, 1998, p.61).

Nessa perspectiva, o trabalho com projetos interdisciplinares visa a garantir a construção de um conhecimento globalizante, rompendo com as fronteiras das disciplinas. Para isso, integrar conteúdos não seria suficiente. É preciso atitude, postura e ousadia interdisciplinares. Atitude de busca, envolvimento, compromisso, reciprocidade diante do conhecimento. Nos projetos educacionais, a interdisciplinaridade se baseia em alguns princípios, entre eles:

1. na noção de tempo: o aluno não tem tempo certo para aprender. Não existe data marcada para aprender. Ele aprende a toda hora e não apenas na sala de aula;

2. na crença de que é o indivíduo que aprende. Então, é preciso ensinar a aprender, a estudar etc. ao indivíduo e não a um coletivo amorfo. Portanto, uma relação direta e pessoal com a aquisição do saber;

3. embora apreendido individualmente, o conhecimento é uma totalidade. O todo é formado pelas partes, mas não é apenas a soma das partes. É maior que as partes;

4. a criança, o jovem e o adulto aprendem quando têm um projeto de vida e o conteúdo do ensino é significativo para eles no interior desse projeto. Aprendemos quando nos envolvemos com emoção e razão no processo de reprodução e criação do conhecimento. A biografia do aluno é, portanto, a base do seu projeto de vida e de aquisição do conhecimento e de atitudes novas. 
Dessa forma, a metodologia desse trabalho por projeto interdisciplinar implica:

1. integração de conteúdos;

2. passar de uma concepção fragmentária para uma concepção unitária do conhecimento;

3. superar a dicotomia entre ensino e pesquisa, considerando o estudo e a pesquisa, a partir da contribuição das diversas ciências;

4. ensino-aprendizagem centrado numa visão de que aprendemos ao longo de toda a vida.

Nessa perspectiva, tomamos como exemplo a descrição de uma ação interdisciplinar do projeto Identidade e Inclusão Social, realizada na Escola de Aplicação, em função do envolvimento dos alunos do Ensino Médio com a temática da produção da diferença e da exclusão social do gênero feminino. Consideramos que gênero é um conceito importante para as questôes educacionais, uma vez que a Educação está implicada na construção de sujeitos. O conceito põe em xeque o caráter "natural" do sujeito feminino ou masculino, mostrando que há um processo de construção do "sujeito de gênero".

Nessa assertiva, através do discurso de várias instâncias que detêm o poder, nossas crianças e jovens aprendem quais comportamentos devem valorizar, quais as atitudes e gestos adequados a cada um dos gêneros, ou seja, ao representar determinadas identidades e excluir ou 'demonizar' outras, o discurso procura, de maneira intencional, constituir e fixar os sujeitos sociais em específicas identidades de gênero e de sexualidade. Nesse sentido, o discurso, muitas vezes, ensina quais são as atitudes consideradas adequadas a uma garota, ou ainda, em veicular, também através das linguagens e dos silêncios, padrões de homem e de mulher, bem como o que podem e devem fazer cada um deles. O currículo escolar, dessa forma, pode e/ou reflete o conflito entre interesses dentro de uma sociedade, entre os valores dominantes que regem os processos educativos e os valores emergentes. No currículo, estão presentes interesses e escolhas sociais, há posiçôes de sujeitos que não possibilitam ver algumas coisas e sim outras que concordam ou não com os valores e as crenças dos grupos dominantes na sociedade. Discutir sobre essa temática de inclusão 
social também é função da escola. Nesse sentido, desencadeou-se um trabalho interdisciplinar, envolvendo, primeiramente, a análise de textos de vários gêneros sobre a temática da produção do feminino. A discussão iniciou a partir da questão de que, conforme Suplicy apud. Beauvoir (1985), não se nasce mulher, torna-se mulher. Não se nasce uma "mulher marionete". É necessário uma educação esmerada, muito puxão de orelha, reprimendas e elogios, e uma boa dose de imitação à figura da mãe, acompanhada de admiração pelo pai, para se produzir uma mulher marionete. Quando a menina nasce, se for de classe média, seu "treinamento" provavelmente terá início no hospital, nas suas roupinhas cor-de-rosa, prosseguindo com o atendimento das enfermeiras que, segundo as pesquisas, falam mais docemente com as meninas do que com os bebês do sexo masculino. As expectativas dos pais quanto à menina são bem definidas. Se alguém perguntar à mãe de um bebê do sexo masculino o que ele será quando crescer, ela fará, provavelmente, divagações que vão do médico ao músico. Se perguntar o que sua filha será quando crescer, a chance de ela responder "Ela vai se casar, ora", será bastante alta.

Com a menina vai ocorrer que, desde pequena, será treinada para a dependência, enquanto seu irmão será treinado para se livrar dela e buscar a autonomia. Seus pais reforçarão suas "gracinhas" infantis enquanto a seu irmão não será permitido ser bobinho. A menina vai aprendendo que ser "boazinha" significa ser dependente e fiel seguidora da opinião dos pais, obedecer, e é nessa tarefa que se empenhará. Esse aprendizado ficará arraigado no mais profundo do seu ser. É um aprendizado que a aliena de si mesma, que se dá de forma inconsciente, que dificilmente ela perceberá. A capacidade de aprendizagem da menina não será usada para emancipar, como a dos meninos, mas para antecipar às exigências dos adultos. Ela é treinada para ser perceptiva do desejo dos outros e não do seu próprio. As meninas são aplaudidas nesse comportamento e o manterão, com alta probabilidade, vida afora. Nesse sentido, o projeto "Identidade e Inclusão Social" buscou, através de um trabalho interdisciplinar, desmitificar os estereótipos femininos produzidos na sociedade a fim de buscar o respeito à diversidade e à equidade social. 
A partir disso, imbricados pela temática, alunos e professores definiram um ponto privilegiado para estabelecer o encontro entre as diversas disciplinas que foi o texto, aqui considerado não só como texto escrito, mas também filmes, músicas, propagandas, enfim, todos os gêneros textuais sociais disponíveis. Dentro do espaço textual, as áreas convergem, se entrelaçam, se expandem em inúmeras direções. Isso acontece porque a natureza dos textos, muito longe de ser fragmentada, é essencialmente relacional. Basta lembrar que um texto não é um aglomerado de frases, mas frases relacionadas e que sua interpretação só chega a bom termo se cada parte for confrontada com as demais.

Durante o desenvolvimento do projeto interdisciplinar, o processo de leitura foi marcado, portanto, por movimentos contínuos de análise e de síntese. $\mathrm{O}$ aluno precisou desdobrar o material em suas partes constitutivas e só pode fazê-lo quando percebeu como foram organizadas e conectadas pelo autor. Por outro lado, de nada vale o leitor identificar as partes do texto se esses pedaços não o levarem a um sentido, a uma unidade. Para encontrar esse sentido, foi preciso reconstituir o todo, discriminar quais são os pontos principais, pesar o que é essencial e o que é secundário. Como se vê, o ato de leitura é todo feito de integração de partes. A leitura bem feita leva à identificação de uma unidade de sentido.

No entanto, para que a leitura de fato se completasse em uma unidade, foi preciso relacionar o texto ao contexto em que foi produzido. O leitor que não é ingênuo sabe que todo texto participa de um debate de escala mais ampla. A despeito de qualquer aparência de neutralidade, há sempre um posicionamento e uma questão posta em debate, pois o texto nasce de uma intenção. Isso se aplica tanto ao texto do jornal, cujo papel é fazer ver o que acontece no mundo, quanto ao romance, cujo personagem principal defende uma visão específica da realidade que, por muito individual e original que pareça, concretiza-se em um sujeito histórico que está localizado em algum tempo e situado em algum lugar. 
Assim, todo texto - até mesmo o ficcional - é um pronunciamento sobre uma realidade. $\mathrm{O}$ autor trabalha com as ideias de seu tempo e da sociedade em que vive, defende ou ataca crenças e valores que escolheu ou pelos quais foi formado. Textos são produções humanas e os homens não vivem no abstrato, cumprem as condições de existência. Todo texto funciona como um receptáculo para os sentimentos, pensamentos, esperanças e medos de um povo em uma determinada época. Eis porque pode realizar um entroncamento das diferentes disciplinas.

Como a sociedade vê a realidade por vários ângulos, porque se encontra dividida em diferentes grupos sociais, que defendem interesses diversos, quando não antagônicos, o mesmo dado pode ser observado por muitos pontos de vista. Analisar as ideias de um texto também foi estudar o diálogo que ele estabelece com outros textos. No nosso caso, este material valeu-se da plurissignificação textual, para realizar a convergência das áreas: debruçadas sobre o mesmo objeto, cada disciplina orientou o olhar do aluno por um viés diferente. $\mathrm{O}$ ponto de articulação entre esses olhares foi o resultado da interdisciplinaridade, o elemento de unidade.

Isso significa que, embora a estratégia de cada área analisar o texto separadamente se repita, as abordagens sempre se renovam porque, a cada aula, as áreas de conhecimento propunham uma atividade de leitura diferente da anterior e renovavam sua composição com as outras. Mudou também o campo de intersecção, porque todo texto é um produto inédito.

Vamos dar um exemplo de como isso acontece, analisando as atividades planejadas para o texto "De Maria à Mariazinha" (SUPLICY, 1985), que foi seguido por uma entrevista feita por professores de História e Língua Portuguesa com personalidades femininas da região. $\mathrm{O}$ gênero textual - a entrevista/depoimento - pressupõe o interesse em dar voz a alguém. Quando esse objetivo encontra-se menos focado, o articulista prefere o discurso indireto. No caso, a introdução chama a atenção do leitor para a importância que um depoimento como aquele tem para que as futuras geraçốes possam compreender um fato da nossa história: 
a discriminação da mulher na sociedade. Sob qual ângulo cada disciplina estabeleceu seu foco de leitura? Qual foi o enquadre escolhido por cada uma? Para entender essa lógica, basta observar os objetivos indicados nas aulas. No caso do nosso exemplo, Fundamentos Sócio-Filosóficos, Geografia e História chamaram a atenção do aluno para a violência e à empregabilidade da mulher em períodos temporais diversos e expandiu essa observação com uma informação fora do texto: a importância que teve para o nosso país a riqueza gerada pelo trabalho feminino. Ressaltar esse fato deu ao aluno possibilidade de relacionar o tamanho da contribuição desse contingente de mão-de-obra e a violência da exploração a ele impingida. Isso, sem dúvida, leva a entender que essa riqueza foi conquistada sem nenhum benefício e com grande sofrimento de quem a produziu.

Essa percepção tornou-se mais emocional, mais afetiva, à medida que vem relatada por quem a experimentou na pele. Nesse caso, a entrevista é uma ótima escolha de gênero, porque promove contato direto com a forma de expressão oral desse grupo. O reconhecimento da importância e dignidade das mulheres é reforçado, pelos estudos dos níveis de linguagem, em Língua Portuguesa, pela compreensão de que as variações linguísticas não constituem erros, mas resultados de processos sociais e históricos. Assim, as disciplinas de Fundamentos Sócio-Filosóficos, Geografia, História e Língua Portuguesa, juntamente com a Oficina de Teatro, convergem para um ponto que as ultrapassa, mas também as une: a valorização de um grupo social que ainda hoje sofre as marcas da violência impostas nos séculos anteriores, estendidas, hoje, como preconceito e desigualdade social. E se as áreas de História, Fundamentos Sócio-Filosóficos e Geografia assinalam essa relação, suscitando a comparação entre passado e presente, a Língua Portuguesa e o Teatro suscitaram a produção coletiva de seminários e debates calorosos como uma forma de reflexão e viagem através dos tempos em busca de uma saída renovadora para um velho padrão de violência e discriminação social. Por fim, um grupo de alunos transformou esses estudos em um gênero textual dramático, culminando com uma apresentação cênica, 
através da oficina de teatro, intitulada De Marionete à mulher, que só foi possível quando as disciplinas trabalharam lado a lado em aspectos distintos de um único problema. No caso que acabamos de analisar, os componentes distintivos das disciplinas (a produção de riqueza, a variedade linguística, a noção de inclusão e equidade, a produção da mulher por várias instâncias que detêm o poder do discurso) serviram ao objetivo comum de diminuir a ignorância que leva ao preconceito e à desvalorização de uma parcela da população que ainda hoje é a mais explorada. Nenhuma das disciplinas citadas conseguiria, sozinha, alcançar esse resultado. Ele só foi possível através desse projeto interdisciplinar que propiciou aos nossos alunos o desenvolvimento da autonomia intelectual e moral, ou seja, esses sujeitos aprenderam através de suas próprias ações sobre os objetos do mundo.

Através da linguagem - e do silêncio - aprendem-se modos de ser homem/mulher, branco/negro, hetero/homossexual, pobre/ rico, com síndromes, surdo, mudo, cego e outros muitos considerados "diferentes" e, portanto, fora da normalidade produzida pelo imaginário social. Nesse sentido, o projeto Identidade e Inclusão social: Educar pela Pesquisa deteve-se, também, à análise da representação e construção, em especial, da identidade da mulher no imaginário social a partir de três eixos norteadores: midiático, biológico e territorial.

A partir desses eixos norteadores foram pesquisados os modos como as identidades da mulher foram construídas socialmente e os mecanismos usados para a produção da diferença no imaginário social, ou seja, como estão sendo subjetivados em diferentes espaços, quais os mecanismos que estão imbricados nessa subjetivação, que efeitos têm esse processo de constituição de determinadas subjetividades. Essa constituição tanto está relacionada a essa produção quanto, mais do que isso, refere-se ao enquadramento da mulher - a partir, principalmente, do disciplinamento de seus corpos - num determinado código de conduta/comportamento considerado como "o normal" e como "o mais adequado" para que se possa partilhar das experiências e, mais ainda, para que se possa viver no mundo contemporâneo. 
Esse projeto tratou, antes, de uma análise que buscou tão somente tentar compreender como as instituições atuam na produção de identidades da mulher e na sua diferenciação no grupo social, sob que lógica operam as diferentes categorias/elementos neles em funcionamento, de que forma e através de que mecanismos tais categorias/elementos são produzidos e, ainda, que efeitos as práticas disciplinares têm na construção de determinados modos de ser quanto às questões de gênero. Não para propor uma destruição e/ou uma transformação desses lugares ou dessas práticas sociais, mas para que, através de "pequenos" detalhes, sutilezas, minúcias, astúcias, arranjos - aparentemente desinteressados - possamos rever algumas de nossas verdades, questionarmos algumas de nossas certezas e, assim, quem sabe, dar vez ao "impossível" em nossa forma de ver, pensar e agir no mundo.

O poder não emana de um único ponto, isto é, ele é exercido por múltiplas forças e grupos que regulam nossa existência. Nesse sentido, muitas instâncias e autoridades também se consideram capazes de vigiar, julgar e marcar as diferenças de gênero. Instâncias que, através de distintos processos, detêm legitimidade social para proclamarem a "verdade" sobre os sujeitos, para demarcarem o certo e o errado, o normal e o patológico; para decidir quem é decente ou indecente, legal ou ilegal. Discursos científicos, religiosos, jurídicos e educacionais produzem esses limites e estabelecem quem está no centro e quem ocupará as margens. Tais discursos não são sempre convergentes. Podem ter sido historicamente concorrentes ou, algumas vezes, complementares. Podem se combinar de formas sutis e intricadas ou podem se contrapor, interpelando distintamente os sujeitos, fazendo-os oscilar e escolher, ou seja, produzindo identidades e diferenças.

Todavia, a história das mulheres, e também sua participação enquanto agente histórico, constitui-se de um objeto historiográfico recente. Os estudos puderam efetivar-se a partir da década de 1960 e receberam tratamento diferenciado, dependendo das correntes historiográficas. Um dos grandes diferenciais para que pudéssemos refletir sobre a participação feminina na 
história deveu-se à abordagem da História Cultural e aos novos documentos historiográficos aceitos em virtude de que eles "nos possibilitam aceder às representações que se fizeram, noutros tempos, sobre as mulheres" (PRIORE, 2001, p. 08).

Ainda que hoje as pesquisas estejam avançando, podemos nos considerar apenas iniciando os estudos acerca de gênero e da concepção de mulher. Assim, urge a necessidade de pensarmos sobre a produção do feminino nas várias instâncias legitimadoras e produtoras de "verdades" pré-estabelecidas, pois

[...] a história moderna das mulheres, idêntica à dos homens, é a história das formas de uma redivisão. Esta história joga-se na cena pública instaurada pela declaração revolucionária igualitária: a história das aparências da igualdade. (DUBY \& PERROT, 1993, p. 5)

Nessa perspectiva, grupos distintos traçam fronteiras diferentes para determinarem a adequação ou marginalidade dos sujeitos. Obviamente, nesse traçado estão inscritas relações de poder. A aprendizagem dos lugares sociais pelos indivíduos é feita desde muito cedo, em múltiplas instâncias e, por vezes, através de mecanismos tão sutis que se torna extremamente difícil percebê-las. Nesse processo, a produção das identidades de gênero tem uma centralidade que é, frequentemente, dissimulada ou negada pelos discursos. Nessa perspectiva, consideramos que a produção das identidades no imaginário social dá-se, no mínimo, por três dispositivos pedagógicos: midiático, biológico e territorial.

\section{Não aguardemos a próxima notícia: sejamos a próxima notícia}

No eixo midiático, interessou-nos descrever as diferenças, mostrar como a TV cria ou reforça processos de inclusão e de exclusão, quanto à classe social, gênero, etnia, geração, profissão. Ou seja, a transformação de nossas vidas em espetáculo está diretamente relacionada a uma série de preconceitos, a uma série 
de valores e de definições a respeito do que são, por exemplo, determinados grupos na sociedade: as mulheres, os negros, os pobres, os adolescentes de classe média, os trabalhadores, etc.

Houve, portanto, a necessidade em "desmanchar" os materiais televisivos a fim de analisar o processo de ensino e de aprendizagem de formas de agir, sentir, atribuir valores, através de uma leitura criteriosa da esfera cultural. Essa foi a tarefa que, certamente, incluiu o debate a respeito das formas de controle da sociedade civil sobre aquilo que é produzido e veiculado pela televisão. Trata-se de uma proposta destinada, nos diferentes níveis de escolarização, a mergulhar na ampla diversidade da produção audiovisual disponível em filmes, vídeos, programas de televisão e que, certamente, nos informará sobre profundas alterações ocorridas nas últimas décadas nos conceitos de cultura erudita, cultura popular, cultura de massa e artes visuais, mas, especialmente, sobre importantes mudanças nos modos de subjetivação, de constituição do sujeito contemporâneo.

Operar científica e pedagogicamente com os produtos midiáticos significa trazer à tona, mais amplamente, o problema da cisão ou da distância entre cultura, sociedade e indivíduo. É indagar sobre, afinal, como cada um de nós participa dos processos de produção de sentidos na nossa sociedade, como cada um de nós está submetido a normas e regras veiculadas não apenas nos lugares tradicionais de "doação de identidade" (COSTA, 1998), mas, sobretudo, nos meios de comunicação. $\mathrm{O}$ estudo midiático busca analisar a distância ou proximidade entre os modos pelos quais, por exemplo, as mulheres brasileiras de diferentes posições sociais são mostradas nos comerciais que vendem bombons, sapatos, máquinas de lavar roupa, temperos para a cozinha, computadores ou cerveja... como se complementam ou entram em choque as conquistas de uma certa sociedade, em termos de suas relações políticas, jurídicas, econômicas e, também, as formas de sociabilidade construídas e veiculadas nos espaços da mídia quanto à produção do feminino? De que modo os sujeitos individuais se sentem, de alguma forma, representados ou excluídos nas narrativas televisivas?

Nesse estudo, buscou-se desmitificar as relações entre a TV e o tratamento que a sociedade confere aos chamados "diferentes". 
Ora, todas as questões em torno do tratamento das diferenças de gênero (de etnia, de geração, de condição social, de profissão, etc.) estão, sobretudo, relacionadas a modos de representação, de enunciação, a formas de interpretação e de comunicação. Ou seja, há uma imensa responsabilidade dos meios de comunicação, particularmente da TV, que aqui nos interessa, no que se refere aos modos de nomear os diferentes. Em que medida essa identidade do diferente é tratada como diferença a ser excluída ou normalizada; ou então, numa outra perspectiva: em que medida esse "outro" (padrão de mulher construído pela sociedade) ganha visibilidade como diferença a ser reconhecida socialmente? Pensando assim, percebemos a grande abrangência e o poder exercido pela mídia que trabalha representaçôes de características físicas e de comportamentos que são importantes para identificação da mensagem do veículo com a sociedade, pensando também mercadologicamente na audiência e no retorno que a comercialização de espaços irá trazer - algo importantíssimo para definições de forma e conteúdo do que será abordado.

Alguns dos materiais analisados pelos alunos mostram justamente que convivem, na TV, distintos tratamentos do "outro", que também já foram discutidos por Fischer (2001) em materiais analisados em suas pesquisas. Segundo essa autora (2001), há modos muito específicos de endereçamento de um comercial, de um filme, de um programa de TV, e esses modos de endereçamento dizem respeito a certas posições de sujeito esperadas.

A partir disso, percebe-se a mídia com suas mensagens como um meio que contribui fortemente para formação da identidade social e individual na sociedade. Priore (2001) ressalta que o fim do século XX inventou, segundo Jean-Paul Aron, um narcisismo coletivo, uma estética insólita do amor de si. A beleza instituiu-se como prática corrente; pior, ela consagrou-se como condição fundamental para as relações sociais. Banalizada, estereotipada, ela invade o quotidiano através da televisão, do cinema, da mídia, explodindo num todo (o corpo nu, na maioria das vezes) ou em pedaços - pernas, costas, seios e nádegas. Nas praias, nas ruas, nos estádios ou nas salas de ginástica, a beleza exerce uma ditadura 
permanente, humilhando e afetando os que não se dobram ao seu império. Percebemos que grande parte das mulheres possuem uma preocupação exacerbada com as suas características físicas (estética e peso) a partir de padrões sociais criados pelos meios de comunicação de massa tanto eletrônicos quanto impressos e que, muitas vezes, colocam em risco a sua saúde para sentirem-se incluídas em determinado grupo. $\mathrm{O}$ elevado aumento de cirurgias plásticas estéticas entre as jovens e o destaque do Brasil no ranking de cirurgias plásticas do mundo reforça esta manifestação social.

Nessa perspectiva, segundo Fischer (2001), há uma expectativa e um desejo por parte dos produtores, criadores, emissores... mas há também uma operação dos sujeitos sobre esses produtos e sobre todo esse processo comunicacional, que é bem mais complexo do que simplesmente a existência de um programa de TV que é veiculado e recebido no espaço da intimidade doméstica. Nessa prática comunicacional, se produzem ou se veiculam modos de ser e de considerar o "outro" como o diferente. Certamente, estão em jogo aqui questões de ordem ideológica, questões que envolvem diretamente relações de poder.

\section{Respeito à diversidade}

Mesmo com vários movimentos em defesa das mulheres, ainda podemos falar em discriminação do sexo feminino e da invisibilidade das mulheres. As mulheres ainda lutam pela igualdade de direitos entre os sexos, o acesso à educação e aos cuidados básicos de saúde. Segundo discurso do secretário-geral da ONU (2005), cerca de 201 milhões de mulheres em todo mundo não têm acesso aos métodos anticoncepcionais eficazes, setenta por cento da população vive atualmente em estado de pobreza e dois terços das pessoas analfabetas são mulheres ou crianças de sexo feminino.

Portanto, quando é debatida a questão da inclusão, pode-se verificar que uma das identidades que está à margem da sociedade, e que 
gera polêmica nesse tipo de discussão, é o estudo de gênero quando é abordada a mulher, pois queiram ou não, as pessoas são rotuladas pelas outras mediante o sexo que apresentam. Pode-se considerar que os diferentes tipos de identidades são produtos da construção da sociedade e da história na qual se mantém a relação de poder.

Defendia-se desde a Grécia antiga que só haveria um sexo biológico, e que dependendo da quantidade de calor recebido no desenvolvimento embrionário, esse corpo seria mais ou menos perfeito. Sendo que o homem, considerado então o corpo perfeito, receberia o calor suficiente para externalizar os órgãos reprodutivos, enquanto que a mulher, ditada como corpo imperfeito, formar-se-ia a partir da falta de calor nos órgãos reprodutivos, os quais permaneceriam internos. A partir de então, a essa escala de perfeição estava associada uma relação hierárquica na sociedade.

Pesquisas mais recentes quanto ao gênero, na área da medicina, revelam que as diferenças entre homens e mulheres perpassam a forma dos seus órgãos sexuais e que há mais diferenças fisiológicas do que supunham tais pesquisadores. Então, se pergunta: que diferenças (fisiológicas, morfológicas e genéticas) são essas que fazem com que mulheres e homens sejam, por vezes, tratados de formas distintas? Será que de fato o homem é mais inteligente que a mulher? Eles possuem uma percepção melhor de espaço? Elas têm uma melhor fluência verbal? $\mathrm{E}$ quanto às doenças, há uma predisposição por ser homem ou mulher? Os hormônios que são distintos entre os sexos, fazem ou não diferença?

Nesse sentido, a partir dos estudos realizados pelos alunos através do Eixo Biológico, observou-se que há características nas quais homens e mulheres apresentam semelhanças, das quais podemos citar, como exemplo, a transmissão das características genéticas associadas aos cromossomos autossômicos, que ditam características tais como formato do rosto, covinha no queixo, albinismo, miopia, cor da pele, formato da boca e do nariz, entre tantas outras. Tais características manifestar-se-ão de acordo com as informações genéticas provindas dos genitores e independem do sexo do indivíduo. 
Nesses estudos, os alunos também constataram que há algumas diferenças. Essas, na maioria, ditadas pelas diferenças na fisiologia dos órgãos e sistemas, na qual podemos citar a ação de diferentes hormônios, sendo que os homens produzem a testosterona, responsável por reger a expressão das características físicas masculinas, e as mulheres, o estrógeno que se equivale à testosterona nos homens e que são produzidos por seus respectivos órgãos sexuais. Essa diferença, por exemplo, hormonal faz com que as mulheres sejam mais suscetíveis ao estresse do que os homens e que tenham uma atividade imunológica mais estimulada e mais eficiente do que eles.

Todavia, essas diferenças são meramente fisiológicas, biológicas e genéticas. Assim, não podemos deixar que essas semelhanças ou diferenças existentes entre homens e mulheres sejam utilizadas para inferiorizar a mulher, para tolher os seus direitos ou para deixá-la à margem da sociedade, excluindo-a e impedindo-a de exercer a cidadania e ter o direito à liberdade de ação e de expressão. Portanto, a partir desses primeiros resultados, busca-se instigar os alunos na continuidade das pesquisas, com o intuito de desmitificar as diferenças produzidas a partir, então, das práticas sociais.

\section{Inclusão no mercado de trabalho}

De acordo com Raffestin (1993), a territorialidade reflete a multidimensionalidade do "vivido" pelos membros de uma coletividade na sociedade em geral. Segundo esse autor, os homens vivem ao mesmo tempo o processo e o produto territoriais por meio de um sistema de relaçóes existenciais e/ou produtivistas. Todas elas são relações de poder uma vez que existe interação entre os agentes que buscam modificar tanto as relaçôes com a natureza como as relações sociais. Sem se darem conta disso, os atores também se modificam.

Nesse aspecto, fica claro o papel que os agentes econômicos desempenham na construção das sociedades nos seus mais diversos segmentos, que se materializam no espaço vivido ou no 
agrupamento de indivíduos, o que Milton Santos (2004) definiu como a "materialidade das intencionalidades".

Contudo, a territorialidade não deve ser confundida como sendo o elementar espaço necessário à sobrevivência. A identificação com o espaço é tomada no processo de socialização, sobressaindo-se da psicologia coletiva. Ela contribui para a elaboração da identidade do grupo. Contrariamente ao que acontece com as "raízes", esses princípios são "portáteis" e permitiram aos migrantes, pioneiros e outros grupos, reconstituir seus horizontes e anseios em novos espaços, ao se apropriarem de novos territórios. Isso é o que permite, inclusive, a cada migrante que se desloca em novos espaços, no interior de uma mesma nação, de uma cidade para outra, refazer seu "território". Portanto, a territorialidade pode permitir tanto processos de inclusão como exclusão.

Nesse sentido, a escolha pelo estudo do gênero feminino deve-se à subordinação histórica da mulher em relação ao homem e pela sua recente participação nas atividades sociais. Durante muito tempo sua participação, também, foi negligenciada pelos historiadores que produziam uma história voltada aos grandes personagens masculinos. Contudo, conforme Georges Dubby e Michelle Perrot (1993), esse panorama histórico já está sendo modificado em alguns países:

Hoje em dia, é na Rússia, no Japão e na Índia, no Brasil e no Norte da África que mais vivamente se manifesta um desejo por parte das mulheres de fazerem a sua história. Como se a escrita desta forma de constituição do sujeito acompanhasse o caminho difícil que leva à democracia. (p. 13)

Dessa forma, o Eixo Territorial buscou compreender e analisar o papel da mulher na sociedade do Vale do Sinos a partir da avaliação de sua inserção no mercado de trabalho e do seu papel na relação capital e trabalho, a partir de uma perspectiva de poder que se estabelece em diversos espaços da sociedade e se materializa no território. A sociedade, assim, cria os mecanismos de poder e, consequentemente, de exclusão que, por sua vez, são materializados no território. 
Assim, o território vai se fragmentando em diversos espaços refletindo o modelo de organização da sociedade. Portanto, há os espaços bem dotados dos serviços para a classe socialmente mais privilegiada e os espaços carentes de serviços urbanos para as classes menos abastadas e, por fim, os espaços dos excluídos tanto territorialmente como socialmente.

Essas pesquisas, realizadas através do Eixo Territorial, buscaram entender como se articulam esses mecanismos de inclusão e exclusão social e, por consequência territorial, a partir do papel que a mulher, tida como minoria na sociedade, desempenha e sofre nesse contexto. Para justificar e reconhecer essa lógica social, busca-se avaliar e comparar a inserção da mulher no mercado de trabalho, mais especificamente, no setor coureiro-calçadista do Vale do Rio dos Sinos.

Alguns estudos, realizados pelos alunos, a partir de artigos de centros de pesquisa demográfica como o DIEESE e IBGE, apontam que as mulheres têm salários menores que os homens, bem como assumem maiores despesas no orçamento familiar. Esses estudos apontam que a presença feminina é crescente nos diferentes ramos da economia e que elas representam a maioria nas universidades brasileiras.

A partir desses estudos, análises, discussões, enfrentamentos, descobertas, os alunos do Ensino Médio foram desafiados a publicarem seus trabalhos em um livro, intitulado "Identidade e Inclusão Social: Educar pela Pesquisa", que foi editado pela Editora Feevale. Os alunos tiveram um momento para apresentar esse livro à comunidade em uma "Noite de Autógrafos".

Assim, a educação pela pesquisa é, portanto, uma modalidade de educar voltada à formação de sujeitos críticos e autônomos, capazes de intervir na realidade com qualidade formal e política. Para intervir nessa realidade, é preciso que o sujeito esteja impregnado no processo de sua aprendizagem. Esse processo inicia-se nos questionamentos das verdades estabelecidas, estende-se pela construção e reconstrução de conhecimentos baseados em argumentos consistentes que, constantemente, são 
avaliados por outros olhos e finaliza-se na comunicação dos objetos da pesquisa. Nessa última parte, temos, além da comunicação oral, a comunicação escrita.

Nesse sentido, a pesquisa é uma possibilidade para alcançarmos esses novos objetivos educacionais a fim de romper com os velhos e tradicionais métodos de ensino, proporcionando, dessa forma, um inovador caminho para a aprendizagem construtora de saberes. Nela o aluno apreenderá através do contato com o mundo vivenciado e em contato com os outros, percebendo que ao agir utiliza certo saber e esse possibilita uma aproximação com a realidade.

\section{Considerações finais}

A ação pedagógica através da interdisciplinaridade aponta para a construção de uma escola participativa e decisiva na formação do sujeito social. O seu objetivo tornou-se a experimentação da vivência de uma realidade global, que se insere nas experiências cotidianas do aluno, do professor e do povo e que, na teoria positivista era compartimentada e fragmentada. Articular saber, conhecimento, vivência, escola comunidade, ambiente, etc. tornou-se, nos últimos anos, o objetivo da interdisciplinaridade que se traduz, na prática, por um trabalho coletivo e solidário na organização da escola. Um projeto interdisciplinar de educação deve ser marcado por uma visão geral da educação, num sentido progressista e libertador. Nessa perspectiva, a interdisciplinaridade deve ser entendida como conceito correlato ao de autonomia intelectual e moral.

Na teoria do conhecimento de Piaget, o sujeito não é alguém que espera que o conhecimento seja transmitido a ele por um ato de benevolência. É o sujeito que aprende através de suas próprias ações sobre os objetos do mundo. É ele, enquanto sujeito autônomo, que constrói suas próprias categorias de pensamento ao mesmo tempo em que organiza seu mundo. 
In-ter-dis-ci-pli-na-ri-da-de. A palavra é comprida e, para a maioria, indecifrável. É talvez o mistério que faz essa ideia ser tão sedutora. O que éser interdisciplinar, então? "É tentar formar alguém a partir de tudo que você já estudou em sua vida", define Ivani Fazenda (2003, p.36). O objetivo dessa metodologia, na opinião dessa autora, serve para "dar visibilidade e movimento ao talento escondido que existe em cada um de nós” (FAZENDA, 2003, p. 79). Em outras palavras, a idéia é falar de questôes profundas de forma simples. Assim, o professor que desenvolver trabalhos interdisciplinares deve desembocar em coisas que eram impossíveis de abordar em educação há anos, como o amor, a equidade social, a inclusão e a beleza. Segundo Fazenda (2001), na dimensão explorada pela interdisciplinaridade, não basta ser bom de conteúdo. É preciso ser belo. "Uma coisa bonita não precisa ser explicada, ela toca você no seu sentido maior, no sentido de existir" (p.52). Por isso, experimentar nossa história e conhecer a essência do que somos é entender e viver a linguagem expressiva, vivenciando o passado no ato cênico do presente para construir o futuro.

Assim, pensar a interdisciplinaridade enquanto processo de integração recíproca entre várias disciplinas e campos de conhecimento "capaz de romper as estruturas de cada uma delas para alcançar uma visão unitária e comum do saber trabalhando em parceria”, conforme afirma Schön (2000), é sem dúvida, uma tarefa que demanda, de nossa parte, um grande esforço no rompimento de uma série de obstáculos ligados a uma racionalidade extremamente positivista da sociedade industrializada.

A interdisciplinaridade enquanto aspiração emergente de superação da racionalidade científica positivista aparece como entendimento de uma nova forma de institucionalizar a produção do conhecimento nos espaços da pesquisa, na articulação de novos paradigmas curriculares e na comunicação do processo de perceber as várias disciplinas; nas determinações do domínio das investigações, na constituição das linguagens partilhadas, na pluralidade dos saberes, nas possibilidades de trocas de experiências e nos modos de realização da parceria. Essa realização 
integrativa-interativa permite-nos visualizar um conjunto de ações interligadas de caráter totalizante e isenta de qualquer visão parcelada, superando-se as atuais fronteiras disciplinares e conceituais.

Face a essas ideias, torna-se necessário repensar a produção e a sistematização do conhecimento fora das posturas científicas dogmáticas, no sentido de inseri-las num contexto de totalidade. Dessa forma, a complexidade do mundo em que vivemos passa a ser sentida e vivida de forma globalizada e interdependente, recuperando-se, assim, o sentido da unidade a qual tem sido sufocada pelos valores constantes do especialismo.

Todavia, trabalhar a interdisciplinaridade não significa negar as especialidades e objetividade de cada ciência. O seu sentido reside na oposição da concepção de que o conhecimento se processa em campos fechados em si mesmo, como se as teorias pudessem ser construídas em mundos particulares sem uma posição unificadora que sirva de base para todas as ciências, e isoladas dos processos e contextos histórico-culturais. A interdisciplinaridade tem que respeitar o território de cada campo do conhecimento, bem como distinguir os pontos que os unem e que os diferenciam. Essa é a condição necessária para detectar as áreas onde se possam estabelecer as conexões possíveis. ${ }^{1}$ Como observa Schön (2000, p.26), "a exigência interdisciplinar impõe a cada especialista que transcenda sua própria especialidade, tomando consciência de seus próprios limites para colher as contribuições das outras disciplinas".

Podemos pensar que um ensino que conciliasse diferentes conceitos, de diferentes áreas; que integrasse as várias disciplinas e fosse capaz de substituir a fragmentação pela interação, daria ao sujeito a oportunidade de aprender a relacionar conceitos e, consequentemente, de construir novos conhecimentos, com muito mais autonomia e criatividade. Mais autonomia, porque

Discutido por Siqueira HSG, Pereira MA. Interdisciplinaridade como superação da fragmentação [citado 2005 Out 23]. Disponível em: http://geocities.yahoo.com.br/ holgonsi/interdisciplinar3 
ele teria aprendido a considerar fatores de diferentes ordens na realização de seus objetivos, inclusive de aprendizagem. Mais criatividade, porque a prática de relacionar implica também a arte de encontrar combinações inéditas, ousadas, saídas novas para velhos problemas. Esse seria um ganho inestimável do processo de ensino no novo milênio.

Segundo Garcia (2003), outro aprendizado importante que essa nova forma de pensar traz em seu bojo é o fato de que as experiências bem-sucedidas de integração incentivam a disposição para buscar relações de complementaridade e estabelecer parcerias. A convivência com o outro, por sua vez, obrigatoriamente impõe a necessidade de administrar os conflitos e desentendimentos provocados pelas diferenças; de compreender a importância de considerar todas as colaboraçóes possíveis; de respeitar e valorizar todos os campos de conhecimento, apesar das divergências.

Nesse sentido, não é exagerado dizer que a convivência das disciplinas pode ser uma estratégia para desenvolver a noção de tolerância. Em suma, isso significa romper com as fronteiras do conhecimento escolarizado, transformando-o em uma postura de compromisso com a reflexão-ação-transformação social, através da razão e da emoção.

\section{Referências}

BRASIL, Secretaria da educação fundamental. Parâmetros Curriculares Nacionais. Brasil: MEC, SEF, 1998.

BEAUVOIR, Simone de. In: SUPLICY, Marta. De Mariazinha a Maria. Petrópolis: Vozes, 1985.

BOUTINET, Jean Pierre. Antropologia do projeto. $5^{\mathrm{a}}$ ed. Porto Alegre: Artmed, 2002.

COSTA, Jurandir Freire. Sem frande nem favor: um estudo sobre o amor romântico. Rio de Janeiro: Rocco, 1998.

DUARTE, Junior. Por que Arte-Educação? São Paulo - Campinas: Papirus, 1983. 
DUBY, Georges; PERROT Michelle (Dir.), Storia delle Donne. Versão portuguesa: História das Mulheres no Ocidente. Porto: Afrontamento, p. 1993-1995, 1990-1991. [5 vs].

FAZENDA, Ivani. (Org). Práticas interdisciplinares na escola. São Paulo: Cortez, 2001.

FAZENDA, Ivani. Interdisciplinaridade: história, teoria e pesquisa. Campinas: Papirus, 2003.

FISCHER, Rosa Maria Bueno. O dispositivo pedagógico da mídia: modos de educar na (e pela) TV. Educ. Pesqui. v 28. nl. São Paulo, 2001; jan.-jun.2001.

GARCIA, Joe. Notas sobre o Professor Interdisciplinar. Revista de Ciências da Educação, Ano 05 n 09 - 2003.

HERNÁNDEZ, Fernando; VENTURA, M. A organização do curriculo por projetos de trabalho: Porto Alegre: Artes Médicas, 1998.

PRIORE, Mary. Corpo a corpo com a mulher. São Paulo: Serviço Nacional de Aprendizagem Comercial, 2001.

RAFFESTIN, Claude. Por uma Geografia do Poder. São Paulo: Ática, 1993.

SANTOS, Milton. A natureza do Espaço: Técnica e tempo, razão e Emoção. 4 ed. São Paulo: Editora da Universidade de São Paulo, 2004.

SCHÖN, Donald. Educando o profissional reflexivo: um novo design para o ensino e a aprendizagem. Porto Alegre: Artmed, 2000.

SUPLICY, Marta. De Mariazinha a Maria. Petrópolis: Vozes, 1985.

TRIVIÑOS, Augusto. Bases Teórico-Metodológicas da Pesquisa Qualitativa em Ciências Sociais. Porto Alegre: Faculdades Ritter dos Reis, 2001.

VENTURA, Paulo Cezar Santos. Por uma Pedagogia de projetos: uma síntese introdutória. Educação \& Tecnologia, CEFET-MG. Belo Horizonte, v 7 n 1, jan.-jun/2002. 